\title{
Prolonged-Release Capsule, Soft Dosage Form
}

National Cancer Institute

\section{Source}

National Cancer Institute. Prolonged-Release Capsule, Soft Dosage Form. NCI

Thesaurus. Code C149872.

Solid single-dose preparation consisting of a soft shell containing a semi-solid or liquid formulation, showing a slower release of the active substance(s) than that of a conventional-release capsule. Prolong ed release is achieved by a special formulation design and/or manufacturing method. Soft prolonged-release capsules are intended for oral use. 